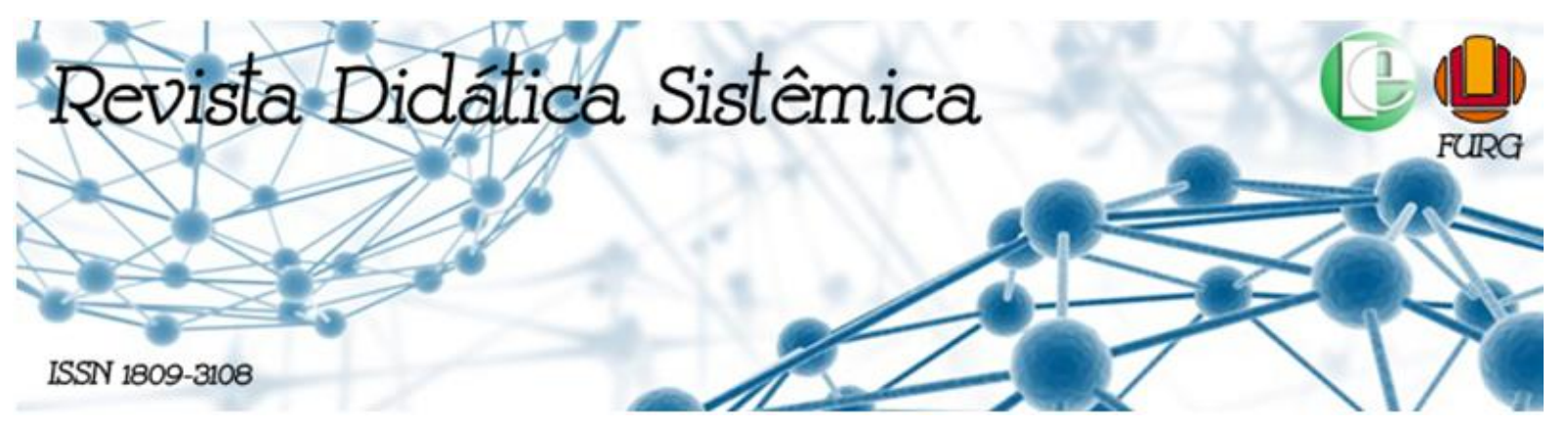

\title{
REPRESENTAÇÕES DE EDUCADORES SOCIAIS SOBRE A EDUCAÇÃO NÃO ESCOLAR
}

\author{
Caroline Silva Pinheiro* \\ Elisandro Schultz Wittizorecki**
}

\begin{abstract}
RESUMO
O presente estudo trata dos processos educativos que ocorrem em instituições de ensino não escolares e teve como objetivos compreender como se organizam os projetos pedagógicos e atividades desenvolvidas nesses espaços de educação e compreender a construção das representações pelos educadores acerca da educação não escolar. Para tanto, realizamos um estudo descritivo por meio de observações, diários de campo e questionários com educadores sociais em duas instituições de Porto Alegre. Assim, compreendemos as particularidades desses locais de educação não escolar. São espaços que ofertam uma diversidade de oficinas, buscam complementar o ensino escolar e acolhem as crianças e suas famílias. Apesar da singularidade das instituições de educação não escolar, encontra-se certa aproximação com a organização e ações das escolas regulares.
\end{abstract}

Palavras chaves: Educação. Educação não-escolar. Educação integral. Professores.

\section{REPRESENTATIONS OF SOCIAL EDUCATORS ON NON-SCHOOL EDUCATION}

\begin{abstract}
This research studies educational processes that take place in non-school teaching institutions and aimed to understand how pedagogical projects and activities developed in these educational spaces are organized and to understand the representations that educators build about non-school education. To this end, we conducted a descriptive study through observations, field diaries and questionnaires with social educators at two institutions in Porto Alegre. Thus, we understand the particularities of these places of non-school education. These are spaces that offer a variety of workshops, seek to complement school education, in addition to welcoming children and their families. Despite the uniqueness of non-school education institutions, there is a certain proximity to the organization and actions of regular schools.
\end{abstract}

Keywords: Education. Non-school education. Integral education. Teachers.

\section{REPRESENTACIONES DE EDUCADORES SOCIALES SOBRE EDUCACIÓN NO ESCOLAR}

\section{RESUMEN}

Este estudio aborda los procesos educativos que se desarrollan en las instituciones de enseñanza no escolar y tiene como objetivo comprender cómo se organizan los proyectos y actividades

\footnotetext{
* Licenciada em Educação Física - ESEFID/UFRGS

** Doutor em Ciências do Movimento Humano. Professor de Graduação e Pós-Graduação na ESEFID/UFRGS
} 
pedagógicas desarrolladas en estos espacios educativos y comprender las representaciones que los educadores construyen sobre la educación no escolar. Con este fin, realizamos un estudio descriptivo a través de observaciones, diarios de campo y cuestionarios con educadores sociales en dos instituciones en Porto Alegre. Ha sido posible entender las particularidades de estos sitios de educación no escolar. Son espacios que ofrecen una variedad de talleres, buscan complementar la educación escolar, además de acoger a los niños y sus familias. A pesar de la singularidad de las instituciones de educación no escolar, parte de los sentidos de su trabajo se acerca de las acciones y de la organización de las escuelas regulares.

Palabras Clave: Educación. Educación no escolar. Educación integral. Profesores.

\section{INTRODUÇÃO}

A escola foi historicamente construída e é ainda representada em nosso tecido social como uma das instituições responsáveis pela formação de pessoas e onde, desde a infância até a idade adulta, frequentamos para aprender algo. Porém, seus conteúdos e abordagens tão semelhantes para diferentes países, contextos e grupos sociais podem ser desfavoráveis para muitos sujeitos, dadas as imensas desigualdades sociais por que somos atravessados. Desse modo, nos processos educativos, é importante a diversidade de possibilidades e a valorização das características de cada membro da sociedade (PÉREZ GÓMEZ, 1998). No entanto, as escolas, predominantemente, tendem a seguir modelos de ensino instituídos para as demandas e traços da sociedade de décadas atrás. Segundo Camargo (2017):

Os objetivos e metodologias da educação formal não respondem às necessidades contemporâneas, visto que a aula é predominantemente expositiva, baseada na transmissão dos conteúdos e na separação das disciplinas, que concebe o aluno enquanto um ser compartimentado, com foco exclusivo no desenvolvimento cognitivo, deixando as demais dimensões constituintes do ser humano negligenciadas à marginalidade no processo escolar (p. 8)

É possível pensar que, para os tempos de hoje, tal modelagem torna-se defasada. As mudanças sociais que vêm ocorrendo nas últimas décadas, com a proliferação e ampliação das tecnologias da informação e comunicação, com a globalização da economia e de tantos processos sociais, produzem grandes alterações no cotidiano dos sujeitos e acabam refletindo na ação pedagógica e na organização das escolas (DIEHL; MOLINA NETO, 2010). Nesse cenário, a escolha de saberes, metodologias, capacitação dos profissionais e interlocução entre alunos e professores são relevantes para um ensino de qualidade (ROCHA; ROZEK, 2017).

Considerando os fatores já mencionados, o processo educativo precisa ocorrer de forma ampla e de modo que seja significativo para os sujeitos, reconhecendo 
e considerando seus sentimentos, emoções, necessidades e ambições (RIBEIRO; PALHARES, 2017). São nos processos de socialização que o humano se inscreve na sociedade, a partir da troca de experiências com o outro e da interação com o meio, possibilitando-o construir sua identidade. Logo, sua trajetória, nos sistemas educativos e fora deles, é importante para sua formação (ROCHA, 2016). Pensando nisso, propiciar mais tempo e espaços de convivência entre os alunos nesses ambientes podem ser alternativas para potencializar o trabalho da educação, já que esses momentos têm potencial socializador, nos quais os sujeitos produzem laço com os colegas e vivem atividades de forma autônoma. Outra possibilidade vai ao encontro do que Medeiros (2008) sustenta: “acreditamos que a educação acontece em vários espaços, não só nos espaços formais, como a sala de aula, a escola, a universidade, mas também, no palco, no espaço da arte, da cultura...” (p. 19). Nesse caminho, Severo (2015) reconhece a necessidade de novos cenários, muitos fora do espaço escolar, e práticas pedagógicas com diferentes possibilidades de ensinar, as quais são relevantes para o desenvolvimento social e para as demandas que marcam o contexto contemporâneo.

Na perspectiva de compreender a educação como fenômeno complexo e em suas múltiplas manifestações, este estudo trata da Educação Não Escolar (ENE). Este campo compreende programas de educação complementares oferecidos no contra turno e, na maioria das vezes, fora da escolarização regular. Proporcionam atividades extraclasses diversificadas e buscam atuar, principalmente, nas demandas sociais presentes no grupo que frequenta suas ações. Em geral, estas instituições não focam exclusivamente em conteúdos escolares, mas, sobretudo, na construção de conhecimento para várias áreas da vida, por meio de trabalhos com esporte, lazer, saúde, meio ambiente (SEVERO, 2015). Constituem uma possibilidade de as crianças terem seu tempo tutelado na contemporaneidade e acessar outros aprendizados e experiências.

Frente ao apresentado, empreendemos um estudo em duas instituições que desenvolvem educação não escolar, cujo problema de pesquisa se constituiu nas seguintes questões: como se organizam os projetos pedagógicos e atividades desenvolvidas nesses espaços de ENE? Quais as representações que educadores constroem acerca da ENE? Nesse sentido, o estudo teve como objetivos: descrever as aulas e as atividades ofertadas em programas de ENE; descrever os princípios e a organização dos projetos pedagógicos das ações de ENE; descrever as compreensões e as representações que os educadores constroem acerca da ENE. 


\section{REFERENCIAL TEÓRICO}

A escola pode ser considerada uma instituição referência na educação de pessoas, cujos dispositivos e saberes precisam passar por transformações e ressignificações para irem ao encontro das necessidades atuais da população. Assim, as mudanças socioculturais interferem, direta ou indiretamente, na organização escolar (DIEHL; MOLINA NETO, 2010). É preciso coerência dos conteúdos ensinados, relacionando-os às problemáticas vivenciadas pelos alunos, tendo sentido significativo para sua formação, já que as demandas, tanto individuais quanto coletivas, afetam o desenvolvimento da sociedade (CAMARGO, 2017).

Os espaços educativos são importantes na formação humana, por isso a escola precisa mediar significados, sentimentos e condutas sociais e estender-se para o desenvolvimento e formação da cidadania nas perspectivas social, educativa e instrutiva (PÉREZ GÓMEZ, 2001). Precisa promover a paz universal, com o objetivo de alcançar compreensão, tolerância e amizade entre nações, grupos raciais e religiosos, respeitando as diferenças culturais (MEDEIROS, 2008). Numa perspectiva freireana, a educação vivida na escolarização tem como uma das finalidades desencadear a formação de seres autônomos, críticos e colaborativos, tratando-se de um processo permanente que gera transformações nos sujeitos (FREIRE, 2002).

Com a necessidade de reconstrução dos tempos, espaços e das propostas educacionais, possibilidades vêm sendo criadas com o objetivo de ir ao encontro das limitações das instituições de educação escolarizada. A educação não escolar é um dos meios educativos que ocorrem fora da escola regular e obrigatória, muitas vezes envolvendo ações coletivas da sociedade (CARVALHO, 2018). Esses processos, atravessados por fatores sociais, políticos e econômicos, relacionados aos culturais, buscam significado ampliado para a formação humana, com troca de experiências e estratégias de ensino e aprendizagens diversificadas, ocorrendo em outros nichos institucionais (SEVERO, 2015).

A educação integral pode ser pensada como uma possibilidade de reinvenção das instituições, com a ampliação do tempo de permanência em espaços socioeducativos, aproveitando, ao máximo, as potencialidades pedagógicas de diferentes lugares da comunidade e da cidade, com a diversificação das atividades e inserção de temas que possibilitem o desenvolvimento das múltiplas dimensões do indivíduo, associados às demandas 
da contemporaneidade (MEDEIROS, 2008). Nesses espaços educativos, busca-se a interação entre os diferentes saberes, envolvendo aspectos culturais, físicos, intelectuais, dentre outros, na formação dos sujeitos (CAVALIERE, 2010). Com abordagens, em sua maioria, ofertadas em modo de oficinas, as práticas corporais mostram-se significativas e recebem prestígio, apresentam-se em grande quantidade como meio de transmissão de valores, constituindo-se em elemento atrativo para a participação dos sujeitos nos projetos (CARVALHO, 2018).

Os programas de educação não escolar vêm sendo reconhecidos como ferramenta importante na educação e formação dos sujeitos. Para que esses programas se materializem, é fundamental a presença de pessoas comprometidas com a causa e seus objetivos. Nesses espaços educacionais, os responsáveis por conduzirem as atividades têm sido predominantemente denominados educadores sociais, demarcando, assim, o foco em sua prática pedagógica e seu significado nas instituições. Recorrentemente, esse educadores se envolvem e estão dispostos a mediar situações ocorrentes na rotina dos educandos (TONDIN, 2011). Têm o papel de ensinar, ultrapassando os conteúdos acadêmicos, e promover a integração entre as pessoas, aproximando grupos distintos (MOURA; ZUCHETTI, 2006).

Geralmente, atuam em contextos de risco ou de vulnerabilidade social, com uma população que vive, muitas vezes, privada de condições básicas de saúde, educação, lazer e renda. Não raras vezes, seu trabalho também incide sobre o atendimento e o acolhimento dessas pessoas, facilitando o convívio familiar e comunitário (ROMERO et al., 2016) e estendendo sua atuação para ações de caráter socioeducativo. A educação torna-se comprometida no cuidado com o outro e o bem viver coletivo (MOURA; ZUCHETTI, 2006). Considerando o ambiente de trabalho, o educador social tem sua ação pedagógica interferida quando se depara com situações cotidianas muitas vezes conflituosas que, com seus conhecimentos e experiências vividas na profissão, precisa refletir e encontrar possibilidades de solução, sem fugir de algum juízo de valores (TONDIN, 2011).

Pensando no educador social como responsável por operar construção de saberes e atender a demandas individuais e coletivas dos alunos, em um espaço voltado para a educação, surge a indagação sobre a proximidade de sua atuação com o convencionado sobre o trabalho docente materializado no ambiente escolar. Ambos operam no ato de ensinar, cada um em seu contexto e com práticas pedagógicas singulares, porém com o mesmo intuito: contribuir na formação de pessoas. Desse modo, a forma de denominar os agentes da educação tem sido mais relacionada ao seu espaço de trabalho que aos efeitos de sua atuação. 
É nesse sentido que nos interrogamos neste estudo: como se organizam os projetos pedagógicos e atividades desenvolvidas nesses espaços de ENE? Quais as representações que educadores constroem acerca da ENE? Para tanto, empreendemos um estudo qualitativo com as decisões metodológicas que apresentamos a seguir.

\section{DECISÕES METODOLÓGICAS}

A pesquisa realizada foi de natureza qualitativa e descritiva (TRIVIÑOS, 1995). Utilizou os seguintes instrumentos para a obtenção das informações: observações, diários de campo, questionário aberto com educadores sociais e análise de documentos das instituições.

O trabalho de campo foi realizado nos meses de setembro, outubro e novembro de 2019, em duas instituições de educação não escolar em Porto Alegre/RS: CESMAR (Centro Social Marista) e Murialdo Social, em que produzimos 10 diários de campo (5 no CESMAR e 5 no Murialdo Social) e 8 questionários com educadores destas instituições (4 no CESMAR e 4 no Murialdo Social).

O CESMAR, localizado no bairro Mario Quintana, oferece atividades aos alunos de três escolas municipais da região, atendendo 820 educandos com idades de seis a 18 anos, permanecendo no centro social até os 14 anos. Lá, trabalham 20 educadores de diferentes áreas, além de nutricionista, assistente social e fonoaudióloga apoiando o trabalho. Para a comunidade, ocorre o empréstimo dos ginásios e do salão para eventos. O projeto é ofertado no turno da manhã (das $8 \mathrm{~h} 30 \mathrm{~min}$ às $11 \mathrm{~h} 40 \mathrm{~min}$ ) e da tarde (das $13 \mathrm{~h}$ às $16 \mathrm{~h} 50 \mathrm{~min}$ ).

O Murialdo Social, situado no bairro São José, atende 109 crianças com idades entre 07 e 14 anos, provenientes de duas escolas municipais da região. O projeto ocorre em três segmentos: projeto social, jovem aprendiz e educativo, conforme idade e necessidade de formação. Conta com oito educadores de diferentes áreas para ofertar oficinas diversificadas. $\mathrm{O}$ projeto social ocorre nos turnos da manhã (das $8 \mathrm{~h} 20 \mathrm{~min}$ às $11 \mathrm{~h} 40 \mathrm{~min}$ ) e tarde (das 13h50min às $16 \mathrm{~h} 45 \mathrm{~min}$ ).

Para a obtenção de informações, fizemos observações das aulas e das atividades e anotações nos diários de campo. Realizamos questionários abertos com alguns educadores que acompanhamos. E obtivemos informações referentes aos princípios e à organização dos projetos pedagógicos de educação não escolar com as coordenadoras das instituições e examinando documentos das instituições. Após, fizemos a leitura dos materiais produzidos, 
destacando trechos significativos referentes ao estudo e construindo unidades de significado. Com isso, construímos aproximações temáticas de modo a produzir categorias que nos permitissem discutir o trabalho empírico em articulação com os objetivos do estudo. Desse modo, construímos três categoriais de análise, cujas interpretações apresentaremos na sequência.

\section{ANÁLISE E DISCUSSÃO DAS INFORMAÇÕES}

\subsection{As aulas e atividades realizadas no CESMAR e no Murialdo Social}

Ao longo do trabalho de campo, observamos diferentes atividades e foi possível identificar uma rotina nas instituições acompanhadas. Geralmente, no início das oficinas, os alunos se organizavam em um círculo junto ao educador e conversavam sobre diversos assuntos de seus interesses e necessidades, e estabeleciam ligação para iniciarem as atividades dirigidas. Nos espaços de educação não escolar, a tarefa do educador social estende-se para além da condução de oficinas, também atendendo às problemáticas e às conquistas dos alunos (MOURA; ZUCHETTI, 2006), como pudemos acompanhar na seguinte passagem do diário de campo:

Sentaram nas cadeiras em círculo e ficaram conversando, o assunto principal foi sobre a filha do educador que estava com 7 dias de vida e alguns alunos relataram experiências de família (diário de 24/09/2019, na oficina de multiesportes - CESMAR).

Após a conversa inicial, os alunos precisaram ficar atentos às tarefas propostas. Pudemos perceber envolvimento e colaboração dos alunos para o funcionamento do projeto, realizando as tarefas e/ou auxiliando no andamento das oficinas. Os educadores buscam a participação efetiva dos alunos, com experiências em várias atividades e tentam fazer com que se tornem protagonistas nas aulas:

Um aluno estava tocando violão e os outros cantando. O educador organizou a parte que todos cantavam juntos e outra que um aluno fazia improvisos de Rap. Ao terminar a música, o educador agradeceu a participação dos alunos e elogiou todos pela aula. (diário de 08/11/2019, na oficina de música - Murialdo Social).

Apesar do bom convívio entre alunos e deste com os educadores, em alguns momentos, foi possível observar conflitos, em que o educador os solucionou por meio de conversas ou negociações. Em um dado momento das observações, um de nós 
foi demandado a fazer a mediação em uma situação de tensão. No entanto, são nesses desentendimentos cotidianos que o educador encontra possibilidades para solução de problemas e integração de práticas educativas (TONDIN, 2011). No relato do diário de campo, encontra-se um desses acontecimentos:

Os meninos estavam se batendo e reclamando dos colegas. Um estava chorando, outro apagou os desenhos das meninas do quadro, um pegou a bola que a educadora pediu para guardar e não jogar na sala. Fui conversando com eles e guardando os materiais, pedi para alguns sentarem para esperar a hora do pátio (diário de 02/10/2019, na oficina de aprendizagem e recreação - CESMAR).

Seguindo a rotina do projeto, na metade do turno, ocorre o intervalo para o lanche, momento em que as turmas se encontram no refeitório. No CESMAR, as crianças encaminhadas pela FASC $^{1}$ também ganham uma refeição quando chegam no local. No Murialdo Social, todas as crianças são encaminhadas pela FASC, por isso ganham duas refeições. Nas duas instituições, é de costume, antes do lanche, alguns minutos de reflexão, realizar uma oração coletiva.

Fomos para o refeitório, os alunos lavaram as mãos e se organizaram nas mesas. Um educador fez o momento da oração. Depois receberam os lanches, enquanto comiam conversavam entre eles e com os educadores (diário de 19/09/2019 Murialdo Social).

Em algumas aulas que acompanhamos, os educadores reservaram um tempo no final do turno para atividades não dirigidas, em que os alunos utilizam os materiais e os espaços para brincarem. Os educadores mediam os conflitos que emergem. Esse período objetiva a integração e autonomia nas aprendizagens, visto que a socialização se torna uma alternativa para troca de experiências e saberes entre os indivíduos (MEDEIROS, 2008). Essa prática foi recorrentemente observada:

Faltando 20 minutos para encerrar as atividades, os alunos foram para a rua em um espaço maior. A maioria dos meninos jogaram futebol na quadra, o restante da turma criou brincadeiras em pequenos grupos; alguns subiram na árvore e nas pedras (diário de 10/09/2019, na oficina de capoeira - CESMAR).

Ao encerrar as atividades, educadores e alunos se direcionam para o portão de saída. o CESMAR, alguns alunos retornam para casa com o ônibus do projeto; outros, com a família ou sozinhos. No Murialdo Social, os alunos utilizam o ônibus da instituição para retornarem às suas escolas e só então são liberados para casa.

\footnotetext{
${ }^{1}$ Fundação de Assistência Social e Cidadania é o órgão gestor da política de assistência social de Porto Alegre, responsável pela oferta de serviços, programas e benefícios que promovam a inclusão de cidadãos, famílias e grupos que se encontram em situação de vulnerabilidade e risco social.
} 
Com as observações, identificamos a oferta de diferentes modalidades nas áreas de aprendizagem (português e matemática), práticas corporais: esportes, recreação, dança e teatro; reciclagem, papel machê, música, culinária, informática, entre outras. As práticas corporais estão significativamente presentes no cronograma, recebem atenção nas oficinas e são tratadas com potencial educativo com transmissão de valores morais e sociais (CARVALHO, 2018). Os educadores são responsáveis por orientarem as turmas ao longo do turno, sendo referência para o andamento do projeto.

O questionamento que surgiu a partir do trabalho de campo é o quanto essas instituições que sustentam sua oferta de educação não escolar, com peculiaridades e objetivos próprios, assemelham-se com grande aproximação em diversos aspectos com a escola regular, sobretudo, no que diz respeito às oficinas com foco no letramento e numeramento, voltadas para o aperfeiçoamento da escrita, leitura e contagem. Pudemos acompanhar algo similar nas práticas esportivas, uma vez que, em muitas delas, têm sua dinâmica como na escola, com o uso da quadra poliesportiva, desenvolvendo modalidades como futebol, handebol, voleibol, bastante hegemônicas na escolarização. A organização das salas com a presença das cadeiras e mesas, quadro e materiais escolares também demarca essa similaridade com o ambiente da escolarização. O que se parece se diferir é a disposição e o maior trabalho em grupo.

Por outro lado, acompanhamos diferenças marcantes quanto à diversidade das oficinas que, em muitas escolas, não estão inseridas no currículo - dança, teatro, música, capoeira, papel machê, reciclagem, informática. Na relação aluno/educador, percebemos uma relação mais afetuosa, uma preocupação na aprendizagem e na participação dos alunos. Preocupação essa que ocorre não só em explicar o conteúdo, mas integrar o grupo durante as atividades. De forma geral, foi possível compreender que há certa proximidade das características desses espaços não escolares com a escola regular.

\subsection{Os princípios e a organização dos projetos pedagógicos}

Por meio das observações e análise dos documentos que conduzem os processos educativos nas instituições estudadas, pudemos retratar e compreender a configuração dos espaços não escolares.

No CESMAR, a ação pedagógica segue ideais de uma perspectiva cristã. O trabalho na instituição busca a melhoria das condições de vida da população residente em locais 
de risco e vulnerabilidade social. Seguindo seus princípios, proporcionam às crianças e jovens a ampliação das áreas de conhecimento, trabalhando muitas dimensões da formação humana e complementando a educação escolar. Seu documento orientador apresenta como objetivos de sua atuação:

Aprendizagem escolar e habilidades artísticas, culturais e esportivas; redução da infrequência e evasão escolar; fortalecimento dos vínculos familiares e comunitários; mudanças comportamentais e nas relações interpessoais no cotidiano das oficinas (CENTRO SOCIAL MARISTA DE PORTO ALEGRE, 2019, p.5).

No Murialdo Social, é utilizado, como base para a organização da ENE, o documento orientador da $\mathrm{SMED}^{2}$ de Porto Alegre (SILVA, 2019), referente à educação integral no município, seguindo quatro eixos: letramento, numeramento, iniciação científica e educação do sensível. Sua formulação objetiva o aumento da jornada escolar, proporcionando aos alunos mais tempo de aprendizagens em espaços além da escola e ampliando as dimensões do conhecimento. Essa ideia pode ser lida no seguinte trecho do documento:

O horário expandido representa uma ampliação de oportunidades e situações que promovam aprendizagens significativas e emancipadoras articuladas entre currículo regular e currículo complementar (SILVA, 2019, p.1).

Ambas as instituições possuem propósitos voltados à educação integral, em que os alunos acessam uma grande variedade de saberes e experiências, assim, desenvolvem suas competências, habilidades e atitudes que ultrapassam a área acadêmica, tendo foco na formação humana. Com isso, é possível depreender o desejo de proporcionar condições e assistência básica aos alunos e familiares, atender à população e propiciar o bem-estar da comunidade (ROMERO et al., 2016).

Para que esses propósitos sejam alcançados, além da diversidade de modalidades e atividades desenvolvidas dentro dos locais de ensino, os educadores incentivam a ampliação da educação e de experiências com outros projetos que proporcionam oportunidades para os alunos acessarem outros ambientes fora das instituições e da comunidade que moram. As crianças e jovens participam de apresentações de dança e teatro, mostras de música e artes, competições esportivas, entre outras. Os processos educativos, além da escola, criam e dão significado ampliado para a formação dos sujeitos (SEVERO, 2015). Dessa forma, abrange a ideia da educação integral, de proporcionar

\footnotetext{
${ }^{2}$ Secretaria Municipal de Educação de Porto Alegre.
} 
ações pedagógicas em diversos locais e aproveitar espaços educativos, possibilitando o desenvolvimento do indivíduo (CAMARGO, 2017).

Os grupos participam de atividades externas, passeios de integração, apresentações e convívio (CENTRO SOCIAL MARISTA DE PORTO ALEGRE, 2019, p. 10).

Com a análise dos documentos referentes às ações pedagógicas das instituições, complementada pelas informações obtidas nas visitas, pudemos perceber aspectos semelhantes entre o CESMAR e o Murialdo Social. Ambos os locais têm como objetivo principal a educação integral, buscando a ampliação das áreas de conhecimento para trabalhar diversas dimensões do indivíduo. Para alcançar seus objetivos de ensino, é organizado um plano de trabalho anual e mensal, no qual os educadores possuem importante participação na formulação das atividades que materializam as premissas pedagógicas das instituições em que atuam.

Embora haja muitas semelhanças na estrutura das duas instituições, a materialização do projeto torna-se distinta na prática. As diferenças aparecem, principalmente, nas ações dos educadores. Observamos que, no CESMAR, a relação dos educadores com os alunos, assim como entre as próprias crianças, parece denotar mais afinidade, atenção, envolvimento e preocupação com as questões individuais dos alunos. Isso foi perceptível nas interações observadas durante as aulas, nos encontros no refeitório, no pátio, ao se cumprimentarem. O convívio entre eles é amigável, ainda que eventualmente brotem alguns conflitos - principalmente entre as crianças menores -, mas estes são solucionados rapidamente.

Os educadores do Murialdo Social, em várias situações, demonstraram atenção nas interações, preocupação e conhecimento em relação aos alunos da instituição, porém de forma mais comedida, com conversas sobre assuntos pessoais, cumprimentos, elogios, troca de ideias nas aulas. Ainda que manifestem esse laço, nessa instituição, ficou mais marcada a posição do educador que transmite conteúdos e o aluno que os recebe.

\subsection{Compreensões e representações dos educadores acerca da educação não escolar}

Nesta seção, buscamos descrever, pela perspectiva dos educadores das duas instituições, as compreensões e as representações acerca da ENE.

Compreendemos que os espaços de educação não escolar buscam proporcionar aos alunos, com intervenções educativas, alternativas de atividades dirigidas no tempo em que 
não estão na escola. Também cumprem a função de trabalhar a convivência com a reflexão de costumes e valores, tendo em vista seus desdobramentos no cotidiano. Carvalho (2018) reconhece a educação não escolar exercida em locais de processos educativos que não sejam a escola, geralmente oferecida em seu turno inverso para os estudantes com ações coletivas na comunidade. Essa ideia é exemplificada na fala da educadora do CESMAR:

O CESMAR é um apoio, ocupa o espaço, eles [os alunos] têm aprendizado, experiência, partilha. Estariam em outros lugares, fazendo outras coisas, até mesmo na rua, aqui é o porto seguro deles. O Cesmar é o coração da comunidade (questionário com a educadora de aprendizagem e recreação - CESMAR).

Como forma de processo educativo, as oficinas têm caráter lúdico e apresentam conteúdos específicos de suas modalidades, mas os educadores reconhecem também como objetivos das aulas a complementação do ensino escolar, principalmente português e matemática. As oficinas de esportes, atividades artísticas e outras, tais como, reciclagem, tecnologias, trabalhos manuais, são destacadas, tendo contribuições valiosas que também deveriam permear a escolarização formal. Esta perspectiva é compreendida a partir do relato do educador de esportes:

Nós estamos com a função da escola, não é só o turno inverso, ensinamos o que eles deveriam ter na escola (questionário com o educador de esporte e convivência - CESMAR).

Assim, parece haver uma tendência de identificação e legitimação das práticas desenvolvidas nessas instituições vinculadas ao discurso escolar. Ao mesmo tempo, nas observações e em outras conversas, os educadores se manifestam diferenciando-se da atuação dos professores que lecionam na escola. Demonstram a intenção de auxiliar os alunos na aquisição de habilidades e competências em diversas dimensões (físico, social, emocional) que fazem parte da formação humana. As funções da educação nesses espaços vão além do ensino dos conteúdos tipicamente escolares: os educadores abordam e enfrentam temáticas relacionadas às necessidades atuais, nas mais diversas dimensões do sujeito (MEDEIROS, 2008). Nessa perspectiva, ouvimos de um educador que:

Trabalho com autoestima, valores, potencial, formação humana, não só os esportes. Mostro uma perspectiva de futuro para a vida deles, passo filme com histórias verídicas, pessoas negras, pobres, que venceram. (questionário com o educador de esporte e convivência - CESMAR).

Para que transformações sociais aconteçam, por meio dos projetos de educação não escolar, os educadores supõem e esperam que os alunos desenvolvam atitudes, respeito 
e empatia, que influenciam suas relações com outros membros da comunidade. Para isso, é importante considerar as individualidades de cada aluno e reconhecer seus interesses, dilemas e contexto em que vivem (RIBEIRO; PALHARES, 2017). Algumas das atitudes que se projetam e produzam efeitos nos alunos são citadas por educadores:

Esses dias ensinamos como tomar banho, que inicia da cabeça para os pés, muitos não sabem direito. A separação do lixo, se comunicar baixo, não precisa ficar gritando (questionário com o educador de letramento e numeramento - Murialdo Social).

Nesses espaços de educação não escolar, os educadores sociais lidam com diversas situações e demandas da vida dos alunos e buscam dar atenção às dificuldades de aprendizagem, conflitos em casa, problemas e angústias pessoais, como é possível acompanhar na seguinte narrativa:

O Marcos está no sexto ano da escola e não é alfabetizado. Quando tem que escrever, um colega ajuda ou eu. Estou ensinando ele escrever as sílabas, um dia escreveu três palavras e ficou muito feliz. Temos uma gravidinha (13 anos), mas ela não quer, não têm os cuidados necessários. E lidamos com tudo isso (questionário com a educadora de aprendizagem e recreação - CESMAR).

O trabalho de campo nos permitiu compreender que os educadores se reconhecem com comprometimento no seu trabalho, manifestando que têm retornos sobre mudanças atitudinais nos alunos. Os educadores escutados constroem representações de que as crianças e jovens conseguem levar efeitos socializadores de seu trabalho nestas instituições para suas famílias e comunidades.

\section{CONSIDERAÇÕES FINAIS}

A partir da análise das informações, identificamos que ambas as instituições, CESMAR e Murialdo Social ofertam uma variedade de atividades e oficinas, sendo muitas dessas práticas corporais relacionadas ao campo da Educação Física. A diversidade de atividades oferecidas aos alunos propicia experiências em diferentes áreas de conhecimento. Esses espaços ainda contribuem com outras ações de potenciais educativos, nas interações, convivências e na rotina das instituições.

Quanto aos princípios e organização dos projetos das duas instituições, percebemos como finalidade a educação integral que segue os eixos da SMED de Porto Alegre: letramento, numeramento, iniciação científica e educação do sensível. Estes eixos se articulam às atividades planejadas ao longo do ano pela coordenação e pelos educadores 
das instituições. Ainda que tenha muitas semelhanças entre as instituições, observamos diferenças na atuação dos educadores, sendo, no CESMAR, as relações com os alunos e outros colegas mais próximas e afetuosas. No Murialdo Social, parece haver menor afinidade entre educadores e alunos, apesar de termos percebido que há preocupação e atenção às suas individualidades.

Compreendemos, por meio das observações e dialogando com os educadores, que os espaços de ENE se tornam locais de práticas educativas, algumas relacionadas aos conteúdos escolares, outras não. Também buscam o ensino de hábitos, costumes e valores, aproximando-se da realidade e contexto social em que se inserem. Além disso, são ambientes de acolhimento para as crianças e jovens, principalmente aqueles que moram em zonas de risco e de vulnerabilidade.

Nesse sentido, reconhecemos a importância da educação não escolar complementar ao da escola, com características semelhantes ao descrito nesse trabalho, visando a uma educação ampliada, nos aspectos físico, social, cognitivo e emocional. Compreendemos, também, que as ações pedagógicas ofertadas em instituições como as pesquisadas são relevantes ferramentas para transformações sociais, uma vez que se constituem em locais de integração dos membros da comunidade, os quais compartilham dos mesmos espaços, materiais, atividades e aprendizagens.

\section{REFERÊNCIAS}

CAMARGO, T. D. de. A educação integral como possibilidade para as problemáticas do século XXI: uma nova educação, para uma nova ciência e um novo ser humano. Dissertação de mestrado. Programa de Pós-graduação de Educação em Ciências: Química da Vida e Saúde. Universidade Federal do Rio Grande do Sul, 2017. Disponível em: https://lume.ufrgs.br/handle/10183/172759. Acesso em: 3 dez. 2019.

CARVALHO, R. de O. As práticas corporais na educação integral em tempo integral: um estudo em duas escolas públicas. Dissertação de mestrado. Programa de Pós-graduação em Ciências do Movimento Humano. Universidade Federal do Rio Grande do Sul, Porto Alegre, 2018. Disponível em: https://www.lume.ufrgs.br/bitstream/handle/10183/187422/001083021.pdf?sequence=1\&isAllowed=y

CAVAliere, A. M. Anísio Teixeira e a educação integral. Paidéia, Ribeirão Preto, v. 20, n. 46, p. 249-259, 2010.

CENTRO SOCIAL MARISTA DE PORTO ALEGRE. Plano Educativo-Evangelizador do Centro Social Marista de Porto Alegre. Porto Alegre, 2019, (mimeo.).

DIEHL, V. R. O.; MOLINA NETO, V. Fluxo Migratório e a Ação Pedagógica dos Professores de Educação Física. Educação \& Realidade, Porto Alegre, v. 35, n. 2, p. 253-277, 2010. Disponível em: https://seer.ufrgs.br/educacaoerealidade/article/view/7615. Acesso em: 3 dez. 2019.

FREIRE, P. Pedagogia da autonomia: saberes necessários à prátia educativa. $25^{\mathrm{a}}$. ed. São Paulo: Paz e Terra, 2002. 
MEDEIROS, R. M. N. Uma educação tecida no corpo. Tese de doutorado. Programa de Pós-graduação em Educação. Universidade Federal do Rio Grande do Norte, 2008. Disponível em: https://repositorio.ufrn.br/jspui/handle/123456789/14144. Acesso em: 3 dez. 2019.

MOURA, E.; ZUCHETTI, D. T. Explorando outros cenários: educação não escolar e pedagogia social. Educação Unisinos, São Leopoldo, v. 10, n. 3, p. 228-236, 2006.

PÉREZ GOMEZ, A. A cultura escolar na sociedade neoliberal. Porto Alegre: Artmed, 2001.

PÉREZ GOMEZ, A. I.; SACRISTÁN, J. G. As funções sociais da escola: da reprodução à reconstrução crítica do conhecimento e da experiência. In: Compreender e Transformar o Ensino. 4 ${ }^{a}$. ed. Porto Alegre: ArtMed, 1998, p. 13-26.

RIBEIRO, Á. M. C.; PALHARES, J. O homeschooling e a crítica à escola: hibridismos e (des)continuidades educativas. Pro-Posições, Campinas, v. 28, n. 2, p. 57-84, 2017.

ROCHA, J. dos S.; ROZEK, M. Quando o aprender na escola é (im)possibilidade. Revista Latinoamericana de Ciencias Sociales, Niñez y Juventud, Manizales (Colômbia), v. 16, n. 1, p. 361-373, 2017.

ROCHA, J. dos S. O aprender como produção humana: os sentidos subjetivos acerca da aprendizagem produzidos por adolescentes em situação de vulnerabilidade social. Dissertação de mestrado. Programa de Pós-graduação em Educação. Pontifícia Universidade Católica do Rio Grande do Sul, 2016. Disponível em http://tede2.pucrs.br/tede2/bitstream/tede/6714/2/DIS_ JULIANA_DOS_SANTOS_ROCHA_COMPLETO.pdf

ROMERO, D. L. et al. Transtornos mentais comuns em educadores sociais. Jornal Brasileiro de Psiquiatria, Rio de Janeiro, v. 65, n. 4, p. 322-329, 2016.

SEVERO, J. L. R. de L. Educação não escolar como campo de práticas pedagógicas. Revista Brasileira de Estudos Pedagógicos, Brasília, v. 96, n. 244, p. 561-576, 2015.

SILVA, I. C. T. Sobre a Educação Integral. Porto Alegre, 2019 (mimeo.).

TONDIN, G. A formação dos educadores sociais de esporte e lazer no Programa Esporte e Lazer da Cidade (PELC) em Porto Alegre. Dissertação de mestrado. Programa de Pós-graduação em Ciências do Movimento Humano. Universidade Federal do Rio Grande do Sul, 2011. Disponível em: https://www.lume.ufrgs.br/bitstream/handle/10183/48909/000828097.pdf?sequence=1\&isAllowed=y

TRIVIÑOS, A. N. S. Introdução à Pesquisa em Ciências Sociais: a pesquisa qualitativa em educação: o positivismo, a fenomenologia, o marxismo. São Paulo, Atlas: 1995. 